\title{
Mountain colonisation, miniaturisation and ecological evolution in a radiation of direct-developing New Guinea Frogs (Choerophryne, Microhylidae)
}

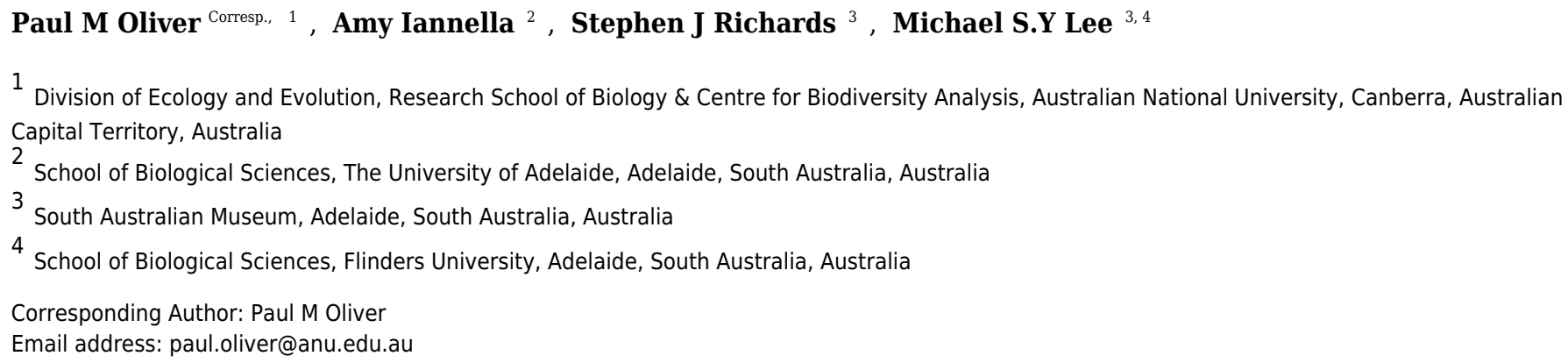

Aims. Mountain ranges in the tropics are characterised by high levels of localised endemism, often-aberrant evolutionary trajectories, and some of the world's most diverse regional biotas. Here we investigate the evolution of montane endemism, ecology and body size in a clade of direct-developing frogs (Choerophryne, Microhylidae) from New Guinea. Methods. Phylogenetic relationships were estimated from a mitochondrial molecular dataset using Bayesian and maximum likelihood approaches. Ancestral state reconstruction was used to infer the evolution of elevational distribution, ecology (indexed by male calling height), and body size, and phylogenetically corrected regression was employed to examine the relationships between these three traits. Results. We obtained strong support for a monophyletic lineage comprising the majority of taxa sampled. Within this clade we identified one subclade that appears to have diversified primarily in montane habitats of the Central Cordillera (> 1000 m a.s.I.), with subsequent dispersal to isolated North Papuan Mountains. A second subclade (characterised by moderately to very elongated snouts) appears to have diversified primarily in hill forests ( $<1000 \mathrm{~m}$ a.s.l.), with inferred independent upwards colonisations of isolated montane habitats, especially in isolated North Papuan Mountains. We found no clear relationship between extremely small body size (adult SVL less than $15 \mathrm{~mm}$ ) and elevation, but a stronger relationship with ecology - smaller species tend to be more terrestrial. Conclusions. Orogeny and climatic oscillations have interacted to generate high montane biodiversity in New Guinea via both localised diversification within montane habitats (centric endemism) and periodic dispersal across lowland regions (eccentric endemism). The correlation between extreme miniaturisation and terrestrial habits reflects a general trend in frogs, suggesting that ecological or physiological constraints limit niche usage by miniaturised frogs, even in 
extremely wet environments such as tropical mountains. 
1 Mountain colonisation, miniaturisation and ecological evolution in a radiation of direct-

2 developing New Guinea Frogs (Choerophryne, Microhylidae)

3

4 Paul M. Oliver ${ }^{1}$, Amy Iannella ${ }^{2}$, Stephen J. Richards ${ }^{3}$, Michael S.Y. Lee ${ }^{3,4}$

5

$6{ }^{1}$ Division of Evolution and Ecology, Research School of Biology \& Centre for Biodiversity

7 Analysis, The Australian National University, Building 116, Daley Road, Canberra, Australian

8 Capital Territory 2061, Australia

$9 \quad{ }^{2}$ School of Biological Sciences, University of Adelaide, Adelaide SA 5005, Australia

$10{ }^{3}$ South Australian Museum, North Terrace, Adelaide SA 5000, Australia.

$11{ }^{4}$ School of Biological Sciences, Flinders University, GPO Box 2100

12 Adelaide SA 5001, Australia

14 Corresponding author: Paul Oliver. Research School of Biology, Australian National University, 15 Building 116, Canberra, 2601, Australia.

16 Email: Paul.oliver@anu.edu.au

Running Header: Mountains and Miniaturised Frogs 


\section{ABSTRACT}

Aims. Mountain ranges in the tropics are characterised by high levels of localised endemism,

often-aberrant evolutionary trajectories, and some of the world's most diverse regional biotas.

Here we investigate the evolution of montane endemism, ecology and body size in a clade of direct-developing frogs (Choerophryne, Microhylidae) from New Guinea.

Methods. Phylogenetic relationships were estimated from a mitochondrial molecular dataset using Bayesian and maximum likelihood approaches. Ancestral state reconstruction was used to infer the evolution of elevational distribution, ecology (indexed by male calling height), and body size, and phylogenetically corrected regression was employed to examine the relationships between these three traits.

37 Results. We obtained strong support for a monophyletic lineage comprising the majority of taxa sampled. Within this clade we identified one subclade that appears to have diversified primarily in montane habitats of the Central Cordillera (> $1000 \mathrm{~m}$ a.s.1.), with subsequent dispersal to isolated North Papuan Mountains. A second subclade (characterised by moderately to very

41 elongated snouts) appears to have diversified primarily in hill forests $(<1000 \mathrm{~m}$ a.s.1.), with

42 inferred independent upwards colonisations of isolated montane habitats, especially in isolated

43 North Papuan Mountains. We found no clear relationship between extremely small body size 44 (adult SVL less than $15 \mathrm{~mm}$ ) and elevation, but a stronger relationship with ecology - smaller 45 species tend to be more terrestrial. 
46 Conclusions. Orogeny and climatic oscillations have interacted to generate high montane

47 biodiversity in New Guinea via both localised diversification within montane habitats (centric

48 endemism) and periodic dispersal across lowland regions (eccentric endemism). The correlation

49 between extreme miniaturisation and terrestrial habits reflects a general trend in frogs,

50 suggesting that ecological or physiological constraints limit niche usage by miniaturised frogs,

51 even in extremely wet environments such as tropical mountains.

52

53 
INTRODUCTION

74

75 Tropical mountains contain some of the most diverse regional biotas in the world, with high

76 levels of localised endemism and often fine elevational turnover in biodiversity (Mayr \&

77 Diamond, 1976; Fjeldså et al., 2012; Merckx et al., 2015; Rosauer \& Jetz, 2015). The origins of,

78 and processes shaping, this exceptional diversity are of great scientific interest, both for

79 improved understanding of the drivers of biological diversity (Janzen, 1967; Hutter et al., 2013;

80 Graham et al., 2014), and for understanding how these highly diverse biotas will be affected by

81 anthropogenic climatic change (Williams et al., 2003; La Sorte \& Jetz, 2010; Freeman \& Class

82 Freeman, 2014).

83 Two broad paradigms to explain high diversity in tropical mountains have been advanced

84 (Fjeldså et al., 2012), and both received support from different studies: a) mountain uplift and

85 climatic change have driven local speciation (the 'cradle' hypothesis; Weir, 2006; Price et al.,

86 2014), or b) mountains have provided refugia, often for specialised taxa that would have

87 otherwise died out due to competition or climatic change (the 'museum' hypothesis; Hutter et al.,

88 2013). In a recent study focused on understanding the biogeographic origins of montane

89 endemics Merckx et al. (2015), suggested they could also be broadly dichotomised into centric

90 endemics (derived from upslope colonisation of lowland taxa) and eccentric endemics (derived

91 via long distance colonisation of cool adapted taxa). 
The large tropical island of New Guinea has arguably the 'most complex orogeny in the world' (Baldwin et al., 2012). The collision of the leading edge of the northwards-moving Australian plate with the westwards-moving southern edge of the Pacific Plate has uplifted a high Central Cordillera ( $>4000 \mathrm{~m}$ a.s.1.) extending nearly the length of the island (Baldwin et al., 2012) (Fig. 1A). These ranges may date from the late Miocene, and high elevation habitats are even younger (Hall, 2002; van Ufford \& Cloos, 2005; Baldwin et al., 2012). Beginning in the Miocene, and continuing with the ongoing rapid uplift of the Huon and Finnisterre Ranges (Fig. 1), additional smaller and more isolated montane regions scattered along northern New Guinea are the uplifted remnants of island arcs that have accreted onto the northern edge of the Australian plate (Hall, 2002; Polhemus, 2007). south of New Guinea (Rawlings \& Donnellan, 2003; Unmack et al., 2013; Georges et al., 2014). It has also been suggested that emerging elevation gradients may have increased speciation rates in some New Guinea radiations, inflating regional alpha diversity (Toussaint et al., 2013, 2014), a species pump model similar to the uplift of the northern Andes (Weir, 2006; Santos et al., 2009). In contrast the endemic montane fauna of the smaller, younger and more isolated mountains of northern New Guinea is particularly poorly known, and there have been few

110 phylogenetically-informed assessments of the origins of endemic taxa in these ranges (Beehler et 111 al., 2012; Oliver et al., 2012a, 2016).

112 The New Guinea frog biota is exceptionally diverse, with $>450$ recognised species, and 113 many more awaiting description (Oliver et al., 2013; Frost, 2015) — far more diverse than nearby

114 landmasses such as Borneo or Australia. Such anuran diversity is remarkable for being 
115 dominated by just two major radiations, of which the most speciose and ecologically diverse is a

116 clade of nearly 250 recognised species of direct-developing microhylids, the Asterophryninae

117 Günther, 1858 (Frost et al., 2006). Their reproductive ecology, wide elevational distribution,

118 high levels of localised endemism, and overall species richness suggest that microhylid frogs

119 may provide an excellent system for understanding how the mountains may have shaped

120 diversification in New Guinea.

121 Choerophryne (including the previously recognised genus Albericus: see Peloso et al.,

122 2015) is a moderately diverse clade (31 recognised taxa) within the Asterophryninae, comprised

123 of small to miniaturised frogs endemic to New Guinea. This genus occurs from hill to upper

124 montane habitats across much of the Central Cordillera and North Papuan Mountains (although

125 they appear to be largely absent from most of the west and southern lowlands of the island)

126 (Günther, 2000; Richards et al., 2000). Broadly, taxa formerly placed in the genus Albericus are

127 mostly climbing frogs with well-developed finger and toe pads, while taxa formerly placed in

128 Choerophryne tend to be more terrestrial, although there are exceptions to this general trend

129 (Kraus \& Allison, 2000; Richards et al., 2007; Günther \& Richards, 2011) (Fig. 2).

130 Choerophryne also includes many miniaturised species, here defined as frogs less than 15

$131 \mathrm{~mm}$ long (Yeh, 2002), some of which approach minimum size limits for tetrapods (Kraus,

132 2010a; Rittmeyer et al., 2012). The water-permeable skin of frogs plays a critical role in shaping

133 both local and regional patterns of diversity and habitat use (Scheffers et al., 2013), with smaller

134 species at greater risk of desiccation than larger species (Tracy et al., 2010). It follows therefore,

135 that smaller size in Choerophryne species may be correlated with occurrence in more humid

136 environments. We hypothesise that such a trend may manifest as a negative correlation between 
137 body size and altitude, due to the existence of reliably moist cloud forest habitats at higher 138 elevations.

139 Here we present an analysis of the phylogenetic relationships and evolution of key traits

140 within Choerophryne. We initially focus on the origins of montane endemism, with a specific

141 prediction being that the older Central Cordillera will be dominated by in situ diversification

142 processes (centric endemism) linked to ongoing uplift, while the younger North Papuan

143 mountains may show evidence of colonisation from the older Central Cordillera (eccentric

144 endemism). We also test the prediction that ecological shifts (arboreal to terrestrial), and shifts in

145 body size (towards extreme miniaturisation) may correlate with occurrence in novel habitats and

146 climatic regimes at higher elevations.

\section{METHODS}

Specimen Selection

152 This study utilised whole specimens and tissue samples deposited in Museum collections (ethics

153 approval was therefore not required). Full details of samples included are given in Tables S1-2.

154 In our final analysis we included 18 of 31 recognised species, plus 11 candidate taxa. Following

155 Vieites et al. (2009) we recognised lineages as distinct OTUs (candidate species) for downstream

156 analysis if they met any two of the following three criteria: a) males with distinctive

157 advertisement calls, b) evidence of morphological differentiation or c) evidence of genetic

158 differentiation (usually greater than $3 \%$ uncorrected pairwise in the 16S rRNA gene (see Table

159 S3 for a summary). Mitochondrial DNA sequences of an additional 11 Choerophryne were 
160 downloaded from GenBank, along with 14 outgroup sequences from 6 other New Guinean

161 microhylid genera. The taxonomic assignation of Choerophryne species is challenging,

162 especially in the absence of calls, so taxonomic designations used in this study should be

163 considered provisional. It is possible further work may demonstrate that some candidate species

164 are conspecific with additional recognised taxa. Full details of samples included are given in

165 Appendix S1.

166

167

168

DNA extraction, amplification, sequencing and alignment

169

170 Whole genome DNA was extracted from frozen or alcohol preserved liver samples using the

171 Gentra Puregene kit protocol (QIAGEN 2011). Sequence data from the $12 \mathrm{~S}$ and $16 \mathrm{~S}$

172 mitochondrial genes was PCR amplified with an annealing temperature of $58^{\circ} \mathrm{C}$ using the

173 primers 12SAL and 12SBH (Palumbi et al., 2002) and 16SL3 and 16SAH (Vences et al., 2003),

174 then purified on MultiScreen PCR $_{384}$ Filter Plates. Sanger sequencing (forward and reverse) of

175 purified PCR product used the BigDye Terminator v3.1 Cycle Sequencing Kit (Applied

176 Biosystems), purified using MultiScreen $\mathrm{SEQ}_{384}$ Filter Plates and sent to the Australian Genome

177 Research Facility (AGRF) for capillary separation.

178 Geneious Pro v5.5.2 (Kearse et al., 2012) was used to align forward and reverse sequence

179 traces and reviewed by eye. The consensus sequences along with sequences from GenBank

180 (Appendix S1) were aligned with 8 iterations of the MUSCLE algorithm under default parameter

181 settings (Edgar, 2004). Hypervariable regions with poor local alignment were removed using 
182 Gblocks v0.91b (Castresana, 2000); of the original 1556 aligned positions, 1347 were retained in

183 final analyses.

184

185 Phylogenetic Analysis

186

187 To assess congruence of topology and support values across methods, we estimated phylogenetic 188 relationships using Bayesian and maximum likelihood approaches. Based on the output of the 189 model selection program MrModeltest (Nylander, 2004) all analyses were performed using the

190 general time-reversible model, allowing for variation in the rate of evolution among sites and

191 including invariable sites $(\mathrm{GTR}+\mathrm{I}+\mathrm{G})$. Both genes were treated as a single partition due to the

192 relatively short sequence length and similar features (i.e. mitochondrial rRNA).

193 The maximum likelihood tree with bootstrap values was produced using RAxML v

194 8.0.26 (Stamatakis, 2006) with bootstrap scores calculated using the rapid bootstrap (-f a)

195 function with 1000 replicates. The Bayesian consensus tree was generated by Mr Bayes 3.2.2

196 (Ronquist et al., 2012) using an unconstrained branch length prior, 4 chains (incrementally

197 heated at temperature 0.2 ), each of 5 million generations with a 1 million generation burn-in and 198 sampling every 200 generations.

199 These topology-only analyses with dense sampling across populations were compared to 200 analyses where we simultaneously estimated phylogeny, divergence dates and trait evolution on 201 species-level trees (see below).

202

203 Trait and biogeographical scoring 
205 We scored each taxon for three traits of interest: i) adult male body size, ii) elevation and iii)

206 maximum calling height of males (as a proxy for arboreality vs terrestriality) (Table S4). These

207 data were scored from genotyped specimens and associated field notes, or extracted from

208 primary literature.

We used a typical measure of size in anurans, the distance from the tip of the snout to the

210 urostyle tip (SUL), which has been previously used in Choerophryne (Günther, 2008). We used

211 the maximum recorded size for males (sex determined by observations of specimens calling).

212 Although some Choerophryne have unusually long snouts, at most these comprised $10 \%$ of the

213 total body length.

214 The maximum elevational range (difference between lower and upper occurrences)

215 obtained for any species was just over 1000 metres, involving three taxa that occur primarily in

216 hill forests, but range into lower montane forests (Choerophryne gracilirostris, C. rostellifer and

217 C. sp A7). Seven taxa are also only known from single sites. To score elevation as a continuous

218 character (for use in phylogenetic regressions) we used the mid-point of records for each lineage

219 (to the nearest $100 \mathrm{~m}$ ).

220 For discrete categorisation of elevation we used the forest classification system presented

221 by Johns (1982): hill forest and lowlands (<1000 m a.s.1.), lower montane (1000-2000m a.s.1.),

222 mid-montane (2000-3000 m a.s.1.) and upper montane (> 3000m a.s.l.). These bands broadly

223 reflect how reducing mean temperatures with elevation shapes the transition from megathermal

224 to microthermal vegetative communities (Nix, 1982). For most taxa, the majority of records were

225 focused in just one of these bands. The small number of taxa whose distributions spanned bands

226 were placed in the band in which the majority of records were concentrated. Finally,

227 Choerophryne laurini is known only from typical lower montane forest on mossy ridge tops in 
228 the Wondowoi mountains between 800-950 metres, although it may also occur in lower montane

229 forest in the Snow Mountains (Richards et al. 2015). This species was coded as lower montane

230 for discrete analyses.

231 To better visualise potential colonisation paths to the isolated North Papuan Mountains,

232 we also devised a further coding system of four states that combined geography and elevation:

233 southern lowland (south of Central Cordillera below $1000 \mathrm{~m}$ a.s.l.), central highlands (Central

234 Cordillera above $1000 \mathrm{~m}$ a.s.1.), northern lowland (south of Central Cordillera below $1000 \mathrm{~m}$

235 a.s.1.) and northern montane (North Papuan Mountains above $1000 \mathrm{~m}$ a.s.1).

236 Male Choerophryne show extensive variation in their typical calling height, from largely

237 terrestrial (e.g. Choerophryne alpestris) to more than 3 metres off the ground (e.g. Choerophryne

238 pandanicola) (Günther \& Richards, 2011). To score calling height as a continuous trait we used

239 the maximum recorded calling height of males, either from the literature or personal

240 observations. We also employed a second scheme for coding calling ecology, by dividing taxa

241 into two broad guilds: a) Terrestrial - species that called predominantly on or very close to the

242 ground on leaf litter or duff (generally less than $50 \mathrm{~cm}$ high); and b) Scansorial - species that

243 usually climb into vegetation and call from (generally more exposed) positions up to several

244 metres high. Two taxa (C. arndtorum and C. microps) for which the majority of calling records

245 are terrestrial but which have occasionally been recorded calling a metre or more above the

246 ground (Günther, 2008), were coded as terrestrial in the discrete character analyses, while the

247 maximum recorded calling height was used in continuous trait based analyses.

249 Ancestral state analyses. 
251 We used BEAST v 1.8.2. (Drummond \& Rambaut, 2007) to co-estimate trait evolution

252 (including ancestral states) with phylogeny and divergence dates. These analyses used a reduced

253 dataset comprising a single exemplar of each genetically and/or morphologically divergent

254 lineage identified in earlier phylogenetic analyses (i.e. recognised or candidate species). The

255 original molecular data for each exemplar was also included. To ensure these analyses were

256 focused on a strongly supported and well-sampled monophyletic group, in these trait analyses we

257 excluded two samples from a highly divergent clade that did not strongly associate with other

258 Choerophryne in estimated phylogenies (see results). Size was $\log _{10}$ transformed. The two

259 discrete variables (elevation and calling ecology) were coded using the MK + strict clock model,

260 which assumes that transformations between states are reversible and occur at the same rate

261 throughout the tree; more complex models were not feasible due to the relatively small tree and

262 number of transformations. Elevation character states were ordered-e.g. shifts from lower- to

263 upper-montane habitats were constrained to involve moving through intervening mid-montane

264 habitats. Analyses were run for 50 million generations, sampling every 50,000 generations. The

265 first $20 \%$ of trees were discarded as burnin and the remaining 800 post-burnin trees from each

266 run were combined to generate the final consensus topology. The final xml file is in Appendix

267 S2. Effective samples sizes (ESS) for all parameters (Tracer v 1.6.0; Drummond \& Rambaut,

268 2007) in both individual and combined BEAST analyses were above 200.

269 BEAST automatically produces an ultrametric tree, however there are no fossil

270 calibrations within Choerophryne, and there has been no recent thorough assessment of rates of

271 mitochondrial DNA evolution in frogs. To provide a rough timescale for Choerophryne, we used

272 a broad consensus molecular evolutionary rate for mitochondrial genes of between $1-2 \%$

273 pairwise divergence per million years, which was incorporated into the prior for the average 
274 substitution (clock) rate. Rates of molecular variation vary extensively (Eo \& DeWoody, 2010),

275 and thus the resultant dates from this analysis are interpreted with caution. Importantly, the

276 ancestral state analyses (above) only require relative rather than absolute branch lengths (e.g.

277 they could still be performed if root age was arbitrarily scaled to 1), so our results are robust to

278 these dating uncertainties.

279

280

\section{Phylogenetic Least Squares Regression}

281

282 The relationship of a) body size to calling ecology and/or elevation, and b) calling ecology to

283 elevation was analysed using BayesTraits v 2.0 (Pagel \& Meade, 2013) across the concatenated

2843200 post-burnin trees from BEAST. For these analyses all variables were included as $\log _{10^{-}}$

285 transformed continuous states. We only included data for lineages in two well-sampled clades of

286 Choerophryne that were strongly supported as sister taxa (see below); other species in the trees

287 were scored as missing data. We also performed regressions on each of these two well-

288 differentiated clades. The Bayesian MCMC implementation of the continuous module was used

289 to regress a) body size against ecology and elevation; and b) ecology against elevation. Eleven

290 million steps were used with the first 1 million discarded for burnin, and 4 runs of BayesTraits

291 were performed and checked for convergence using Tracer v 1.6.0 (Drummond \& Rambaut,

292 2007). Pagel \& Meade (2013) state that the significance of a variable can be assessed either by

293 comparing harmonic means (for analyses with and without the variable), or observing whether

294 the estimated distribution of that variable (e.g. 95\% HPD) excludes 0. Due to issues around the

295 use of harmonic means to estimate marginal likelihoods (Xie et al., 2011), we adopted the latter 296 approach. 


\section{RESULTS}

299

\section{Phylogenetic relationships and lineage diversity.}

301

302 Bayesian and maximum likelihood analyses identified three major lineages of Choerophryne 303 (Fig. 3, Fig. S1). Clade A comprised the majority of sampled taxa that were formerly placed in

304 the genus Albericus, Clade B included all taxa with a moderate to pronounced rostral projection

305 formerly placed in Choerophryne sensu stricto. Clade C comprised two scansorial taxa lacking

306 distinctive rostral projections that occur south of the Central Cordillera in hill forest, and on the

307 Finnistere Ranges (north-east New Guinea) in hill to lower montane forest respectively.

308 A sister taxon relationship between Clades A and B was strongly supported in all

309 analyses (Posterior Probability 1.0, bootstrap support $>90$ ). Clade $\mathrm{C}$ was more divergent and

310 there was no evidence that it forms the sister group to Clade $\mathrm{A}+\mathrm{B}$ (or any other microhylid

311 lineage). All basal relationships between the sampled New Guinea microhylid genera were

312 poorly supported, but these were not the focus of this study.

313 Within Clade A we identified two strongly supported primary lineages, with the major

314 split being between a clade of two lower montane and hill forest taxa from the south side of the

315 Central Cordillera, and several clusters of species from across the Central Cordillera and North

316 Papuan Mountains, including derived terrestrial taxa from mid to upper montane habitats $(C$.

317 alpestris and C. brevicrus).

318 Within Clade B there were three well supported primary lineages: one comprising three

319 deeply divergent taxa (C. burtoni and two unnamed taxa) from hill forest to mid-montane 
320 habitats on the Central Cordillera; a further lineage of large-bodied and very long-snouted taxa

321 from hill and lower montane forest in northern New Guinea; and finally a diverse

322 conglomeration including lineages from hill and lower montane forests in northern New Guinea,

323 in addition to one taxon from south of the Central Cordillera (C. gracilirostris).

324 In all three major clades we identified lineages (candidate species) that were deeply

325 divergent from, and could not be confidently assigned to, recognised species. This was most

326 pronounced in Clade A, which includes a number of scansorial species that are difficult to

327 diagnose on the basis of external morphology.

328

329 Ancestral States analyses

330

331 The dated species tree for ancestral states analysis (Figs. 4-5) was congruent with our densely-

332 sampled, undated molecular phylogeny (Fig. 3). Character states for Clade C were not included

333 in most ancestral state analyses due to phylogenetic uncertainty and the relatively small number

334 of lineages. These analyses highlighted the contrasting evolutionary trajectories of the two 'core'

335 clades of Choerophryne (A \& B). In all analyses including elevation, hill forest habitats (largely

336 distributed between 0-1000 $\mathrm{m}$ a.s.l.) were inferred as the ancestral habitat for both Clades A and

337 B. Clade A was inferred to have diversified primarily within montane habitats during the late

338 Miocene (14 out of 15 nominal taxa), including more recent upslope shifts into mid and upper-

339 montane zones (Fig. S2). Independent colonisation from eccentric origins to the North Papuan

340 Mountains is inferred when geography is included (especially in the Foja Mountains) (Fig. 4A).

341 In contrast Clade B was centred on hill forest habitats, but with 2-4 relatively recent upslope

342 (eccentric) shifts into montane habitats in mostly distantly related taxa, again mainly occurring in 
343 isolated North Papuan Mountains (specifically Japen Island, and the Foja and Torricelli

344 Mountains) (Fig. 4B, Fig. S2).

345 Miniaturised species $(<15 \mathrm{~mm})$ occurred across the phylogeny (Fig. 5), implying that

346 multiple lineages of Choerophryne have independently evolved very small body size. Taxa in the

347 predominantly scansorial Clade A tended to be larger than those in the more terrestrial clade B.

348 Calling ecology was relatively labile across the genus, with multiple shifts between

349 terrestrial and scansorial calling, the latter being inferred as the ancestral state for the common

350 ancestor of clades A and B (Fig. S2). However, there were contrasting patterns across the two

351 clades. Clade A was inferred as largely scansorial with a small number of shifts towards

352 terrestrial calling, Clade B included a majority of taxa (9 out of 14) that call from on, or close to,

353 the ground (this state was accordingly inferred as ancestral) with 3 transitions to scansorial

354 calling.

355

356 Phylogenetic Regressions

357

358 All BayesTraits runs converged well before the burnin, and the concatenated runs yielded ESS of

359 all parameters $>1000$. In the analysis relating body size to ecology and/or elevation, both ecology

360 and elevation (considered together following Pagel \& Meade 2013) exhibited significant

361 phylogenetic structure (Lambda for all taxa was significantly positive: mean $0.55 ; 95 \% \mathrm{HPD}=$

$3620.12,0.98$ ). Ecology (as indexed by calling height) was positively associated with body size in

363 the all taxa analysis (mean $=0.09,95 \% \mathrm{HPD}=0.03,0.15$ ). In analyses focusing on specific

364 clades this relationship was also positive, although the HPD included zero for Clade A (mean=

$3650.1 ; 95 \% \mathrm{HPD}=-0.01,0.19)$, but not Clade $\mathrm{B}($ mean $=0.1 ; 95 \% \mathrm{HPD}=0.01,0.20)$. 

coefficient centred almost exactly on 0 when all taxa were included (mean $=0.01,0.95 \%$ HPD $=$ $-0.11,+0.11)$. Analyses of the two main clades showed positive and negative relationships, although in both cases the HPD again included 0, suggesting the relationships were weak or insignificant (Clade A mean $=0.24,95 \%$ HPD $=-0.06,0.5$; Clade B mean $=-0.05,95 \%$ HPD $=$ $0.20,0.08)$.

Calling height was weakly negatively related to elevation, although in all cases the HPD again spanned zero (all taxa mean $=-0.65,95 \% \mathrm{HPD}=-1.27,0.04$; Clade $\mathrm{A}$ mean $=-1.1,95 \%$ $\mathrm{HPD}=-2.49,0.15$; Clade B mean $=-0.74,95 \%$ HPD $=-1.62,-0.03)$. Removal of three high elevation (>2500 $\mathrm{m}$ a.s.1.) taxa in Clade A that live in mossy grasslands where there are few arboreal habitats weakened this relationship further, resulting in a $95 \%$ highest probability posterior distribution that more broadly included 0 (mean $=-0.47,95 \% \mathrm{HPD}=-1.06,0.16)$.

\section{DISCUSSION}

Despite the biological wealth and high endemism of the New Guinea Mountains (Tallowin et al. 2016) and emerging evidence for major evolutionary radiations (Toussaint et al., 2014; Givnish et al., 2015), only a small number of phylogenetic studies of lineages with distributions centred presumed to have comparatively low vagility. 
389 Species diversity and phylogeny

390

391 Molecular assessments of amphibian diversity on tropical islands over the last decade have

392 revealed exceptionally high levels of previously unrecognised diversity (Meegaskumbura et al.,

393 2002; Vieites et al., 2009). However, while New Guinea already has the most diverse insular

394 frog fauna in the world (over 450 recognised species; Frost, 2015), molecular assessments of

395 frog diversity in this region are scarce. While taxonomy was not the focus of this study, we

396 uncovered 12 candidate species (although it remains possible that further work will show some

397 of these to be conspecific with recognised taxa), in addition to three new taxa recently named

398 (Iannella et al. 2014; 2015). Molecular studies of other New Guinea microhylid frogs

399 (Mantophryne) have also revealed a diversity of deeply divergent lineages (Oliver et al., 2013),

400 and further fieldwork and integration of molecular, morphological and acoustic analyses seem

401 certain to cement New Guinea's position as a global hotspot of amphibian diversity.

402 Clades A and B together formed a strongly supported monophyletic group, but the overall

403 monophyly of all three sampled lineages of Choerophryne was not strongly supported (or

404 rejected). There are however morphological synapomorphies uniting all three lineages of

405 Choerophryne (see Burton \& Zweifel, 1995), and their monophyly was also recently supported

406 based on a phylogenomic study including examplars of all three major lineages (Peloso et al.,

407 2015). The non-monophyly of Choerophryne in our analyses could be an artefact of rapid

408 diversification and/or the short rapidly saturating loci used in this study. Resolution and further

409 discussion of the phylogeny and generic taxonomy of Choerophryne will require larger nuclear

410 gene-based datasets and sampling of taxa from other regions of New Guinea. However because 
411 of uncertainty in basal relationships, in this study we focused ancestral state analyses on the well-

412 sampled and supported clades A and B.

413 There were distributional gaps in our genetic sampling (Fig. 4B). However, recent

414 surveys in western New Guinea (upper Mamberamo, Fakfak mountains) have indicated that

415 Choerophryne (which are usually easy to locate) are absent or rare, suggesting this disjunction

416 reflects genuine absence (Günther, 2000; Richards et al., 2000). Another gap is the Papuan

417 Peninsula, where endemic Choerophryne are found (Fig. S3). However, none of these taxa are

418 shared with central New Guinea, suggesting that taxa in this region-which is geologically very

419 distinctive - will have their own history. Furthermore, while future addition of taxa from this

420 region into phylogenetic datasets is a research priority, we consider it unlikely to change the

421 broadly reciprocal patterns of elevational distribution and montane colonisation between clades

422 A and B in central New Guinea that we discuss below.

423

424 Complex origins of montane endemism

425

426 Uplifting tropical mountains have been shown to be 'cradles' of young diversity in diverse

427 regional bird communities (Weir, 2006; Price et al., 2014). Recent work on beetles, mammals

428 and birds has suggested a similar association between diversification and the recent uplift of

429 mountains in New Guinea (Meredith et al., 2010; Toussaint et al., 2014; Irestedt et al., 2015). In

430 this study we complement such work by providing the first molecular phylogeny of a vertebrate

431 clade (Clade A within Choerophryne) that is both moderately diverse (15 nominal taxa), and

432 almost entirely endemic to the New Guinea Highlands ( $>1000 \mathrm{~m}$ a.s.1.). Our phylogeny suggests

433 Clade A colonised lower montane habitats first, possibly by the mid-Miocene, while higher 
434 altitude taxa (i.e. $>2000 \mathrm{~m}$ a.s.l.) in Clade A are younger (Pliocene origin). This pattern is

435 broadly consistent with progressive upslope colonisation as the Central Cordillera gained height

436 through the late Miocene, and during the Pliocene, suggesting that recent mountain uplift has

437 played a key role in the diversification of this lineage.

438 On the other hand we find weak evidence that New Guinea mountains have functioned as

439 a 'museum'. One potential example from Choerophryne is a clade in the Central Cordillera

440 region (burtoni, $s p \mathrm{~B} 2$ and $s p \mathrm{~B} 3$ ) that shows outwardly disjunct distributions and deep

441 divergences (estimated 10 mya in our analyses). However, when compared to deeply divergent

442 relict bird lineages or high phylogenetic endemism of mammals (Jønsson et al., 2010; Rosauer \&

443 Jetz, 2015) in the New Guinea mountains, our data do not at this stage provide strong evidence

444 that relict taxa have inflated montane diversity in Choerophryne.

445 A further striking result of this study is the inference of both centric and eccentric origins

446 of montane diversity in the younger, lower elevation, more isolated and poorly known North

447 Papuan Ranges. These ranges are home to numerous endemic taxa or isolated populations

448 (Richards et al., 2009; Oliver et al., 2011, Oliver et al. 2012a,b, 2016; Beehler et al., 2012), but

449 in most cases these are clearly related to, or even conspecific with, montane taxa occurring

450 elsewhere in New Guinea (e.g. 100\% of birds are allopatric isolates of lineages occurring in

451 montane habitats elsewhere; Beehler et al., 2012). In Choerophryne two lineages in Clade A

452 show a similar pattern; they appear to be endemic to montane habitats in the north Papuan

453 Mountains (not found below around $1000 \mathrm{~m}$ a.s.1.), related to taxa otherwise known only from

454 montane Central Cordillera habitats, and unknown from the intervening lowlands (Richards \&

455 Suryadi, 2003). This apparent pattern of eccentric origins suggest that lower montane forests in 
456 New Guinea have a dynamic climatic history, including periods of major elevational depression

457 similar to those inferred elsewhere in the tropics (Colinvaux et al., 1996; Zhuo, 1999).

$458 \quad$ However, ancestral state analyses of our well-sampled Clade B, also provides strong

459 evidence for at least two and potentially three independent derivations of North Papuan montane

460 endemics from surrounding lowland taxa (centric endemism) (Fig. 4A). Detailed fine scale

461 sampling is required to understand the processes that have shaped this endemism; elevational

462 segregation may be an outcome rather than a driver of speciation (Caro et al., 2013; Freeman,

463 2015). However, regardless of the exact process, this represents the first strong evidence that

464 endemic montane vertebrates have arisen de novo in northern New Guinea from largely lowland

465 lineages. These contrasting origins of endemism suggest that the young and isolated North

466 Papuan Mountains may provide excellent opportunities for comparative analyses of the

467 processes driving montane endemism in young tropical mountains.

$468 \quad$ Finally, mountain uplift may also inflate regional diversity at lower elevations by

469 isolating formerly continuous populations of lowland taxa (vicariance). In New Guinea there is

470 already compelling evidence that the uplift of the Central Cordillera has isolated northern and

471 southern vicars in lowland and aquatic taxa (Rawlings \& Donnellan, 2003; Georges et al., 2014),

472 and potentially also lower montane taxa (Irestedt et al., 2015). However, our sampling of

473 Choerophryne did not reveal extensive north-south vicariance, although one possible exception

474 is a recently described pair of potential sister taxa in Clade B from hill and lower montane forest;

475 C. gracilirostris (south) and C. grylloides (north) that are estimated to have diverged around 10

476 mya. This general lack of signal for north-south vicariance is unsurprising given the majority of

477 species in the two clades are associated with hill and montane forest, and are less likely to be

478 isolated by mountain uplift than lowland or aquatic taxa. 


\section{At the lower size limits of vertebrates; correlates of repeated miniaturisation}

481

482

483

484

485

486

487

488

489

490

491

493

494

495

496

497

498

499

500

501

A number of anuran lineages that approach the minimum size limits for vertebrates have been recently described (Wollenberg et al., 2008; Kraus, 2010a; Rittmeyer et al., 2012, Lehr \& Coloma, 2008; Kraus, 2010, 2011; Wollenberg et al., 2011; Rittmeyer et al., 2012), and it has been suggested that miniaturised frogs may represent an often overlooked, but important ecological guild in tropical areas (Rittmeyer et al., 2012). Broadly, three patterns are globally apparent in miniaturised frogs: most lack a free-swimming tadpole stage (Estrada \& Hedges, 1996); occur in wet tropical and usually insular regions; and are more-or-less terrestrial (Kraus, 2010a; Rittmeyer et al., 2012). Across the six different genera of Papuan microhylids that contain miniaturised taxa (Aphantophryne, Austrochaperina, Choerophryne, Cophixalus, Oreophryne and Paedophryne) all three of these correlates are evident.

Our analyses further indicate that within Choerophryne there have been at least three relatively recent shifts towards extremely small body size (three lineages with SUL $\sim 15 \mathrm{~mm}$ or less), all of which are inferred in lineages that call on or close to the ground. This plasticity of body size and ecology of Choerophryne contrasts with conservatism of these same features in another miniaturised genus of Papuan microhylids, Paedophryne (Rittmeyer et al. 2012). Patterns of evolution across both genera do however strongly support the hypothesis that physiological or ecological constraints limit miniaturised taxa to a terrestrial lifestyle. Most recognised taxa missing from our analyses are moderate sized (SUL $>15 \mathrm{~mm}$ ) and scansorial, and likely belong in Clades A and C. Their inclusion in our analyses is unlikely to change the correlation between terrestriality and small size. 
503 elevation and either ecology (calling height) or body size, as might be expected if desiccation

504 risk is decreased at higher elevations (Scheffers et al., 2013). This lack of pattern may indicate

505 that for frogs of extremely small size, physiological or ecological pressures associated with

506 microhabitat use are a greater constraint on body sizes than elevation-related variation in

507 climates. Unlike the correlation between terrestriality and small size in which we are confident,

508 and which mirrors a broader pattern, further analysis including both Choerophryne taxa missing

509 from our dataset, and other microhylid genera is probably needed to refine understanding of the

510 potentially much more nuanced relationships between body size, ecology and elevation.

511 Finally, Choerophryne provides a striking example of an insular frog lineage that has

512 undergone ecological diversification, with repeated shifts between scansorial and relatively

513 terrestrial ecologies, reflected in significant reduction or even loss of terminal discs and

514 shortening of limbs (Günther, 2008; Kraus, 2010b; Günther \& Richards, 2011). Similar

515 ecological diversity and morphological plasticity has also been observed in other microhylid

516 lineages in New Guinea, as well as in other island systems such as Madagascar and the

517 Philippines (Andreone et al., 2005; Köhler \& Günther, 2008; Blackburn et al., 2013). In contrast,

518 microhylids generally seem to be peripheral (and usually terrestrial or fossorial) components of

519 frog diversity in continental regions (see Duellman, 1999).

\section{CONCLUSIONS}

522

523 Our new phylogeny and ecophenotypic data for the microhylid frog genus Choerophryne

524 indicates that montane areas have been colonised via a complex suite of biogeographic 
525 processes, especially upslope colonisation and speciation in presumably novel highland habitats

526 and dispersal between montane islands, and that the relative importance of these processes has

527 differed across even closely related lineages. Choerophryne also shows a correlation between

528 extremely small size and utilisation of terrestrial habitats, mirroring a global pattern that suggests

529 that, in frogs, ecological or physiological constraints largely limit extremely miniaturised taxa to

530 terrestrial microhabitats in tropical areas.

531

532 ACKNOWLEDGEMENTS

533 We thank the numerous landholders in New Guinea for access to their land, the National

534 Research Institute and Department of Environment and Conservation (now Conservation and

535 Environment Protection Authority) in Papua New Guinea for research and export approvals, the

536 South Australian Museum for access to material in their care, and to the numerous other research

537 organisations and NGOs that facilitated the collection and examination of material used in this

538 study. We thank Mark Scherz and an anonymous reviewer for their extensive helpful comments

539 on earlier versions of this manuscript.

541 REFERENCES

542 Andreone F., Vences M., Vieites D.R., Glaw F., \& Meyer A. (2005) Recurrent ecological

543 adaptations revealed through a molecular analysis of the secretive cophyline frogs of

$544 \quad$ Madagascar. Molecular Phylogenetics and Evolution, 34, 315-322.

545 Baldwin S.L., Fitzgerald P.G., \& Webb L.E. (2012) Tectonics of the New Guinea Region. 
547 Beehler B., Diamond J., Kemp N., Scholes E., Milensky C., \& Laman T. (2012) Avifauna of the 548 Foja Mountains of western New Guinea. Bulletin of the British Ornithologist's Club, 132, $549 \quad 1-18$.

Blackburn D.C., Siler C.D., Diesmos A.C., Mcguire J.A., Cannatella D.C., \& Brown R.M.

551

552

553

554

555

556

557

558

559

560

561

562

563

564

565 (2013) An adaptive radiation of frogs in a southeast asian island archipelago. Evolution, 67, $2631-2646$.

Burton T.C. \& Zweifel R.G. (1995) A new genus of genyophrynine microhylid frogs from New Guinea. American Museum Novitates, 3129.

Caro L.M., Caycedo-Rosales P.C., Bowie R.C.K., Slabbekoorn H., \& Cadena C.D. (2013) Ecological speciation along an elevational gradient in a tropical passerine bird? Journal of Evolutionary Biology, 26, 357-374.

Castresana J. (2000) Selection of conserved blocks from multiple alignments for their use in phylogenetic analysis. Molecular Biology and Evolution, 17, 540-552.

Colinvaux P.A., Liu K.-B., Oliveira P., Bush M.B., Miller M.C., \& Kannan M.S. (1996) Temperature depression in the lowland tropics in glacial times. Climatic Change, 32, 19-33.

Drummond A.J. \& Rambaut A. (2007) BEAST: Bayesian evolutionary analysis by sampling trees. BMC evolutionary biology, 7, 214.

Duellman W.E. (1999) Patterns of Distribution of Amphibians. The Johns Hopkins University Press, Baltimore. 
566 Edgar R.C. (2004) MUSCLE User Guide. Nucleic Acids Research, 32, 1-15.

567 Eo S.H. \& DeWoody J.A. (2010) Evolutionary rates of mitochondrial genomes correspond to

568 diversification rates and to contemporary species richness in birds and reptiles. Proceedings

569 of the Royal Society of London: Biological sciences, 277, 3587-3592.

570 Estrada A.R. \& Hedges S.B. (1996) At the Lower Size Limit in Tetrapods: A New Diminutive

571 Frog from Cuba (Leptodactylidae: Eleutherodactylus). Copeia, 4, 852-859.

572 Fjeldså J., Bowie R.C.K., \& Rahbek C. (2012) The Role of Mountain Ranges in the

573 Diversification of Birds. Annual Review of Ecology, Evolution, and Systematics, 43, 249-

574265.

575 Freeman B.G. (2015) Competitive Interactions upon Secondary Contact Drive Elevational

576 Divergence in Tropical Birds. The American Naturalist, 186, 470-479.

577 Freeman B.G. \& Class Freeman A.M. (2014) Rapid upslope shifts in New Guinean birds

578 illustrate strong distributional responses of tropical montane species to global warming.

579 Proceedings of the National Academy of Sciences, 111, 4490-4494.

580 Frost D.R. 2014. (2015) Amphibian Species of the World. Website:

$581 \quad$ http://research.amnh.org/vz/herpetology/amphibia/

582 Frost D.R., Grant T., Faivovich J., Bain R.H., Haas A., Haddad C.F.B., De Sá R.O., Channing

583 A., Wilkinson M., Donnellan S.C., Raxworthy C.J., Campbell J. a., Blotto B.L., Moler P.,

584 Drewes R.C., Nussbaum R. a., Lynch J.D., Green D.M., \& Wheeler W.C. (2006) The

585 Amphibian Tree of Life. Bulletin of the American Museum of Natural History, 297, 1-291.

586 Georges A., Zhang X., Unmack P., Reid B.N., Le M., \& Mccord W.P. (2014) Contemporary 
genetic structure of an endemic freshwater turtle reflects Miocene orogenesis of New Guinea. Biological Journal of the Linnean Society, 111, 192-208.

589 Givnish T.J., Spalink D., Ames M., Lyon S.P., Hunter S.J., Zuluaga A., Iles W.J.D., Clements

590 M.A., Arroyo M.T.K., Leebens-mack J., Endara L., \& Kriebel R. (2015) Orchid

591 phylogenomics and multiple drivers of their extraordinary diversification. Proceedings of 592 the Royal Society of London: Biological Sciences, 282, 1814.

593 Graham C.H., Carnaval A.C., Cadena C.D., Zamudio K.R., Roberts T.E., Parra J.L., McCain 594 C.M., Bowie R.C.K., Moritz C., Baines S.B., Schneider C.J., VanDerWal J., Rahbek C., 595 Kozak K.H., \& Sanders N.J. (2014) The origin and maintenance of montane diversity: 596 integrating evolutionary and ecological processes. Ecography, 37, 711-719.

597 Günther R. (2000) Albericus laurini species nova, the first record of the genus Albericus (Anura, 598 Microhylidae) from the west of New Guinea. Mitteilungen aus dem Museum fur $599 \quad$ Naturkunde in Berlin Zoologische Reihe, 76, 167-174.

600 Günther R. (2008) Descriptions of four new species of Choerophryne (Anura, Microhylidae) 601 from Papua Province, Indonesian New Guinea. Acta Zoologica Sinica, 54, 653-674.

602 Günther R. \& Richards S.J. (2011) Five new microhylid frog species from Enga Province, Papua 603 New Guinea, and remarks on Albericus alpestris (Anura, Microhylidae). Vertebrate $604 \quad$ Zoology, 61, 343-372.

605 Hall R. (2002) Cenozoic geological and plate tectonic evolution of SE Asia and the SW Pacific: 606 computer based reconstructions, model and animations. Journal of Asian Earth Sciences, $607 \quad 20,353-431$. 
608 Hutter C.R., Guayasamin J.M., \& Wiens J.J. (2013) Explaining Andean megadiversity: the 609 evolutionary and ecological causes of glassfrog elevational richness patterns. Ecology $610 \quad$ Letters, 16, 1135-1144.

611 Iannella A., Oliver P., Richards S. 2015. Two new species of Choerophryne (Anura, 612 Microhylidae) from the northern versant of Papua New Guinea's Central Cordillera. 613 Zootaxa 4058:332-340. DOI: 10.11646/zootaxa.3753.5.6.

614 Iannella A., Richards S., Oliver P. 2014. A new species of Choerophryne (Anura, Microhylidae) 615 from the Central Cordillera of Papua New Guinea. Zootaxa 3753:483-493. DOI:

$616 \quad$ 10.11646/zootaxa.3753.5.6.

617 Irestedt M., Batalha-Filho H., Roselaar C.S., Christidis L., \& Ericson P.G.P. (2015) Contrasting 618 phylogeographic signatures in two Australo-Papuan bowerbird species complexes (Aves: 619 Ailuroedus). Zoologica Scripta, 45, 365-379.

620 Janzen D.H. (1967) Why mountain passes are higher in the tropics. The American Naturalist, $621 \quad \mathbf{1 0 1}, 233-249$.

622 Johns R.. (1982) Plant Zonation. Biogeography and Ecology of New Guinea (ed. by J.. Gressitt), 623 pp. 309-330. Dr W. Junk Publishers, The Hague.

624 Jønsson K.A., Fabre P., Ricklefs R.E., \& Fjeldså J. (2010) Major global radiation of corvoid 625 birds originated in the proto-Papuan archipelago. Proceedings of the National Academy of $626 \quad$ Sciences, 108, 2328-2333.

627 Kearse M., Moir R., Wilson A., Stones-Havas S., Cheung M., Sturrock S., Buxton S., Cooper A., 628 Markowitz S., Duran C., Thierer T., Ashton B., Mentjies P., \& Drummond A. (2012)

629 Geneious Basic: an integrated and extendable desktop software platform for the 

organization and analysis of sequence data. Bioinformatics, 28, 1647-1649.

631 Köhler F. \& Günther R. (2008) The radiation of microhylid frogs (Amphibia: Anura) on New 632 Guinea: A mitochondrial phylogeny reveals parallel evolution of morphological and life 633 history traits and disproves the current morphology-based classification. Molecular $634 \quad$ Phylogenetics and Evolution, 47, 353-365.

635 Kraus F. (2010a) New genus of diminutive microhylid frogs from Papua New Guinea. ZooKeys, $636 \quad 48,39-59$.

637 Kraus F. (2010b) An unusual new species of Albericus (Anura: Microhylidae) from Mount 638 Giluwe, Papua New Guinea. Proceedings of the Biological Society of Washington, 123, 1$639 \quad 7$.

640 Kraus F. (2011) At the lower size limit for tetrapods, two new species of the miniaturized frog 641 genus Paedophryne (Anura, Microhylidae), 88, 71-88.

642 Kraus F. (2013) A New Species of Choerophryne (Anura : Microhylidae) from Papua New 643 Guinea, with remarks on the taxonomic status of Albericus. Zoosystematics and Evolution, $644 \quad 89,283-291$.

645 Kraus F. \& Allison A. (2000) A Review of the Endemic New Guinea Microhylid Frog Genus 646 Choerophryne. Herpetologica, 57, 214-232.

647 La Sorte F.A. \& Jetz W. (2010) Projected range contractions of montane biodiversity under 648 global warming. Proceedings of the Royal Society of London: Biological Sciences, 277, 649 3401-10.

650 Lehr E. \& Coloma L.A. (2008) A Minute New Ecuadorian Andean Frog ( Anura: 
652 Mayr E. \& Diamond J.M. (1976) Birds on islands in the sky: Origin of the montane avifauna of 653 Northern Melanesia. Proceedings of the National Academy of Sciences, 73, 1765-1769.

654 Meegaskumbura M., Bossuyt F., Pethiyagoda R., Manamendra-Arachchi K., Bahir M., 655 Milinkovitch M.C., \& Schneider C.J. (2002) Sri Lanka: an amphibian hot spot. Science, $656 \quad 298,379$.

657

658

659

660

661

662

663

664

665

666

667

668

669

670

671

672

Merckx V.S.F.T., Hendriks K.P., Beentjes K.K., Mennes C.B., Becking L.E., Peijnenburg K.T.C.A., Afendy A., Arumugam N., de Boer H., Biun A., Buang M.M., Chen P.-P., Chung A.Y.C., Dow R., Feijen F.A.A., Feijen H., Soest C.F., Geml J., Geurts R., Gravendeel B., Hovenkamp P., Imbun P., Ipor I., Janssens S.B., Jocqué M., Kappes H., Khoo E., Koomen P., Lens F., Majapun R.J., Morgado L.N., Neupane S., Nieser N., Pereira J.T., Rahman H., Sabran S., Sawang A., Schwallier R.M., Shim P.-S., Smit H., Sol N., Spait M., Stech M., Stokvis F., Sugau J.B., Suleiman M., Sumail S., Thomas D.C., van Tol J., Tuh F.Y.Y., Yahya B.E., Nais J., Repin R., Lakim M., \& Schilthuizen M. (2015) Evolution of endemism on a young tropical mountain. Nature, 524, 347-350.

Meredith R.W., Mendoza M.A., Roberts K.K., Westerman M., \& Springer M.S. (2010) A phylogeny and timescale for the evolution of Pseudocheiridae (Marsupialia: Diprotodontia) in Australia and New Guinea. Journal of Mammalian Evolution, 17, 75-99.

Nix H. (1982) Environmental determinants of biogeography and evolution in Terra Australis. Evolution in Arid Australia (ed. by W.R. Barker and P.J.M. Greenslade), pp. 47-66. Peacock Publications in association with Australian Systematic Botany Society and ANZAAS, Frewville, South Australia, 
673 Nylander J.A.A. (2004) MrModeltest v2. Evolutionary Biology Centre, Uppsala University, .

674 Oliver L.A., Rittmeyer E.N., Kraus F., Richards S.J., \& Austin C.C. (2013) Phylogeny and 675 phylogeography of Mantophryne (Anura: Microhylidae) reveals cryptic diversity in New 676 Guinea. Molecular Phylogenetics and Evolution, 67, 600-607.

677 Oliver P.M., Krey K., Mumpuni, \& Richards S. (2011) A new species of bent-toed gecko 678 (Cyrtodactylus, Gekkonidae) from the North Papuan Mountains. Zootaxa, 55, 22-32.

679 Oliver P.M., Richards S.J., \& Sistrom M. (2012a) Phylogeny and systematics of Melanesia's 680 most diverse gecko lineage (Cyrtodactylus, Gekkonidae, Squamata). Zoologica Scripta, 41, $681 \quad 437-454$.

682 Oliver P., Richards S., Mumpuni M., \& Rösler H. (2016) The Knight and the King: two new 683 species of giant bent-toed gecko (Cyrtodactylus, Gekkonidae, Squamata) from northern 684 New Guinea, with comments on endemism in the North Papuan Mountains. ZooKeys, 562, $685 \quad 105-130$.

686 Oliver P., Richards S., \& Tjaturadi B. (2012b) Two new species of Callulops (Anura:

687 Microhylidae) from montane forests in New Guinea. Zootaxa, 44, 33-44.

688 Pagel M. \& Meade A. (2013) BayesTraits: Manual.

689 Palumbi S.R., Martin A., Romano S., McMillan W.O., Stice L., \& Grabowski G. (2002) The 690 simple fool's guide to PCR version 2. University of Hawaii, Honululu,

691 Peloso P.L. V, Frost D.R., Richards S.J., Rodrigues M.T., Donnellan S., Matsui M., Raxworthy

692 C.J., Biju S.D., Lemmon E.M., Lemmon A.R., \& Wheeler W.C. (2015) The impact of 693 anchored phylogenomics and taxon sampling on phylogenetic inference in narrow-mouthed 
695 Polhemus D. (2007) Tectonic Geology of Papua. The Ecology of Papua (ed. by A. Marshall and 696 B. Beehler), pp. 137-164. EricOey, Richmond.

Price T.D., Hooper D.M., Buchanan C.D., Johansson U.S., Tietze D.T., Alström P., Olsson U., Ghosh-Harihar M., Ishtiaq F., Gupta S.K., Martens J., Harr B., Singh P., \& Mohan D. (2014) Niche filling slows the diversification of Himalayan songbirds. Nature, 509, 222-5.

Rawlings L.H. \& Donnellan S.C. (2003) Phylogeographic analysis of the green python, Morelia viridis, reveals cryptic diversity. Molecular Phylogenetics and Evolution, 27, 36-44.

Richards S.J., Dahl C.S., \& Hiaso J. (2007) Another new species of Choerophryne (Anura: Microhylidae) from Southern Highlands Province, Papua New Guinea. Transactions of the Royal Society of South Australia, 131, 135-141.

705

706

707

708

709

710

711

712

713

Richards S.J., Iskandar D.T., \& Allison A. (2000) Amphibian and reptiles recorded on the RAP survey in the Wapoga area, Irian Jaya, Indonesia. A Biological Assessment of the Wapoga River Area of Northwestern Irian Jaya, Indonesia. RAP Bulletin of Biological Assessment

Richards S.J., Oliver P.M., Krey K., \& Tjaturadi B. (2009) A new species of Litoria (Amphibia: Anura: Hylidae) from the foothills of the Foja Mountains, Papua Province, Indonesia. Zootaxa, 13, 1-13.

Richards S. \& Suryadi S. (2003) A Biodiversity Assessment of Yongsu-Cyclops Mountains and the Southern Mamberamo Basin, Papua, Indonesia. A Biodiversity Assessment of Yongsu- 
715

716

717

718

719

720

721

722

723

724

725

726

727

728

729

730

731

732

733

734

\section{Cyclops Mountains and the Southern Mamberamo Basin, Papua, Indonesia: RAP Bulletin}

of Biological Assessment 25 (ed. by S.J. Richards and S. Suryadi), pp. 76-80. Conservation International, Washington, DC.

Richards S.J, Tjaturadi B., Mumpuni \& Puradyatmika, P. (2015) Field guide to frogs of the Mimika region - Papua, Indonesia. PT Freeport Indonesia, Mimika.

Rittmeyer E.N., Allison A., Gründler M.C., Thompson D.K., \& Austin C.C. (2012) Ecological guild evolution and the discovery of the world's smallest vertebrate. PLOS ONE, 7, 1-11.

Ronquist F., Teslenko M., Van Der Mark P., Ayres D.L., Darling A., Höhna S., Larget B., Liu L., Suchard M.A., \& Huelsenbeck J.P. (2012) Mrbayes 3.2: Efficient bayesian phylogenetic inference and model choice across a large model space. Systematic Biology, 61, 539-542.

Rosauer D.F. \& Jetz W. (2015) Phylogenetic endemism in terrestrial mammals. Global Ecology and Biogeography, 24, 168-179.

Santos J.C., Coloma L.A., Summers K., Caldwell J.P., Ree R., \& Cannatella D.C. (2009) Amazonian amphibian diversity is primarily derived from late Miocene Andean lineages. PLoS Biology, 7, 0448-0461.

Scheffers B.R., Phillips B.L., Laurance W.F., Sodhi N.S., Diesmos A., \& Williams S.E. (2013) Increasing arboreality with altitude: a novel biogeographic dimension. Proceedings of the Royal Society: Biological Sciences, 280, 20131581.

Stamatakis A. (2006) RAxML-VI-HPC: Maximum likelihood-based phylogenetic analyses with thousands of taxa and mixed models. Bioinformatics, 22, 2688-2690.

735 Toussaint E.F.A., Sagata K., Surbakti S., Hendrich L., \& Balke M. (2013) Australasian sky 
736 islands act as a diversity pump facilitating peripheral speciation and complex reversal from

737 narrow endemic to widespread ecological supertramp. Ecology and Evolution, 3, 1031$738 \quad 1049$.

739 Toussaint E.F.A, Hall R., Monaghan M.T., Sagata K., Ibalim S., Shaverdo H. V, Vogler A.P.,

740 Pons J., \& Balke M. (2014) The towering orogeny of New Guinea as a trigger for arthropod 741 megadiversity. Nature communications, 5, 4001.

742 Tracy C.R., Christian K.A., \& Richard Tracy C. (2010) Not just small, wet, and cold: Effects of 743 body size and skin resistance on thermoregulation and arboreality of frogs. Ecology, 91, $744 \quad$ 1477-1484.

van Ufford A.Q. \& Cloos M. (2005) Cenozoic tectonics of New Guinea. AAPG Bulletin, 89, 119-140.

Unmack P.J., Allen G.R., \& Johnson J.B. (2013) Phylogeny and biogeography of rainbowfishes 748 (Melanotaeniidae) from Australia and New Guinea. Molecular Phylogenetics and $749 \quad$ Evolution, 67, 15-27.

750 Vences M., Kosuch J., Glaw F., Böhme W., \& Veith M. (2003) Molecular phylogeny of 751 hyperoliid treefrogs: Biogeographic origin of Malagasy and Seychellean taxa and re752 analysis of familial paraphyly. Journal of Zoological Systematics and Evolutionary $753 \quad$ Research, 41, 205-215.

754 Vieites D.R., Wollenb, Erg K.C., Andreone F., Köhler J., Glaw F., \& Vences M. (2009) Vast 755 underestimation of Madagascar's biodiversity evidenced by an integrative amphibian 756 inventory. Proceedings of the National Academy of Sciences of the United States of 
America, 106, 8267-8272.

758 Weir J.T. (2006) Divergent Timing and Patterns of Species Accumulation in Lowland and 759 Highland Neotropical Birds. Evolution, 60, 842-855.

760 Williams S.E., Bolitho E.E., \& Fox S. (2003) Climate change in Australian tropical rainforests:

761 an impending environmental catastrophe. Proceedings of the Royal Society of London:

$762 \quad$ Biological sciences, 27, 1887-92.

763 Wollenberg K.C., Vieites D.R., Van Der Meijden A., Glaw F., Cannatella D.C., \& Vences M.

764 (2008) Patterns of endemism and species richness in Malagasy cophyline frogs support a

765 key role of mountainous areas for speciation. Evolution, 62, 1890-1907.

766 Xie W., Lewis P.O., Fan Y., Kuo L., \& Chen M.-H.H. (2011) Improving Marginal Likelihood

767 Estimation for Bayesian Phylogenetic Model Selection. Systematic Biology, 60, 150-160.

768 Yeh J. (2002) The effect of miniaturized body size on skeletal morphology in frogs. Evolution;

769 international journal of organic evolution, 56, 628-41.

770

Zhuo Z. (1999) Response of altitudinal belts of vegetation to the late quaternary climatic changes

771 in tropical Asia. Geographical Research, 18, 96-104.

772

773

774 Supporting Information.

775 
776 Appendix S1. Supplementary tables and figures. Specimen numbers, locality information and

777 GenBank accession numbers for Choerophryne specimens included in analyses (Table S1);

778 GenBank accession details for outgroup samples (Table S2); genetic distance data for species

779 and candidate lineages (Table S3); and summary data on body, elevational distribution and

780 calling height for Choerophryne (Table S4). Bayesian tree for all samples (Figure S1); Trait

781 evolution in the major lineages of Choerophryne estimated using BEAST (Figure S2); and

782 summary of museum records for Choerophryne grouped by phenotype (Figure S3).

783 Appendix S2. BEAST input file for ancestral state analyses

784 Appendix S3. Treefile for chronogram estimated in BEAST with ancestral states.

785

786 Figure 1. Map of New Guinea.

787 Stratified by major elevation bands and with key areas of montane forest denoted. 


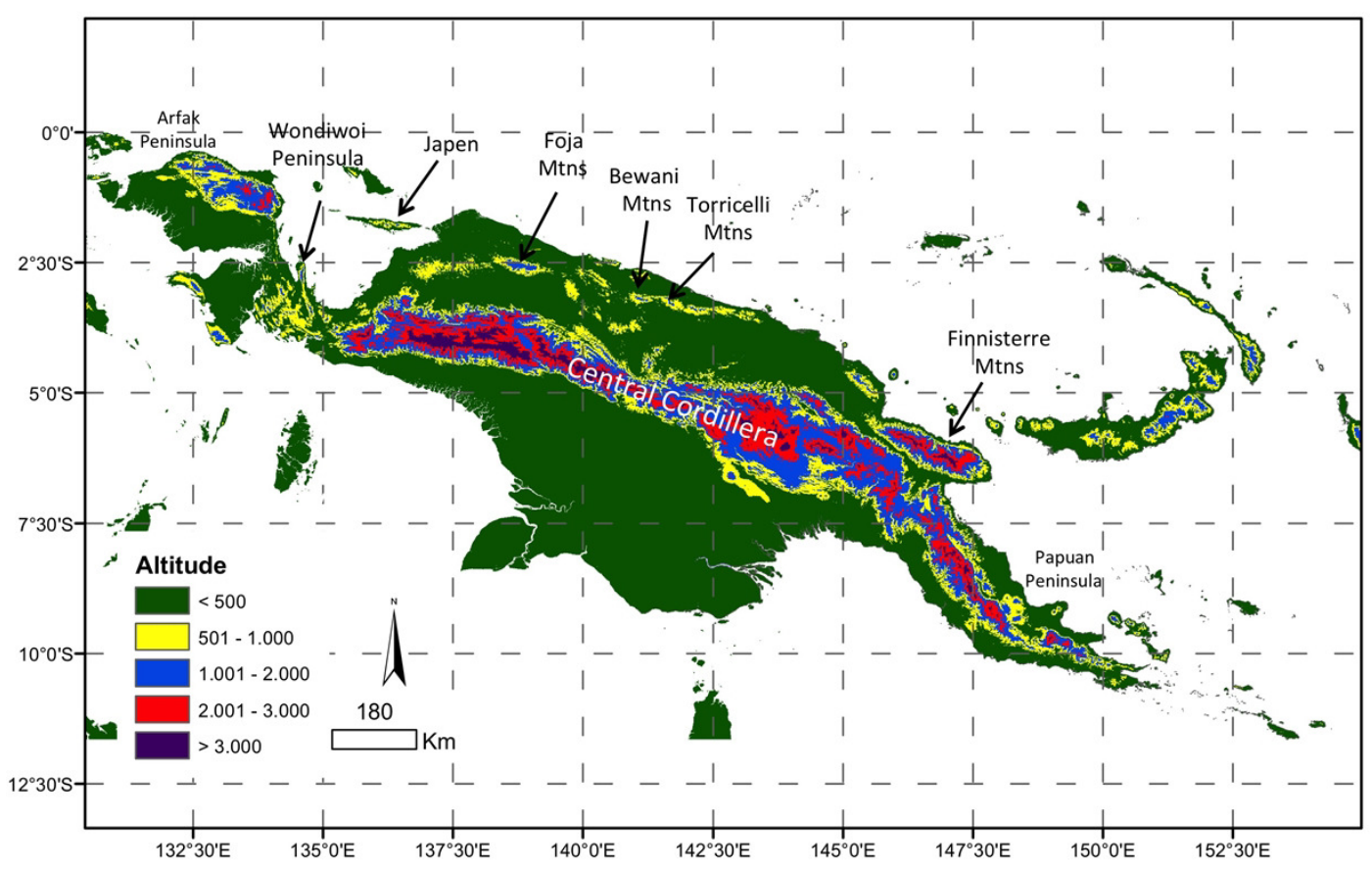


799 Figure 2. Representative species of Choerophryne.

800 A) Choerophyrne alpestris upper montane moss fields, Central Cordillera, terrestrial; B)

801 Choerophyrne spA7 hill forest, southern foothills, scansorial; C) Choerophyrne spB1 lower 802 montane forest, Foja Mountains, terrestrial; D) Choerophyrne proboscidea hill forest forest, 803 northern lowlands, scansorial. Photographs courtesy S. Richards (A,B,D) and T. Laman (C).

804

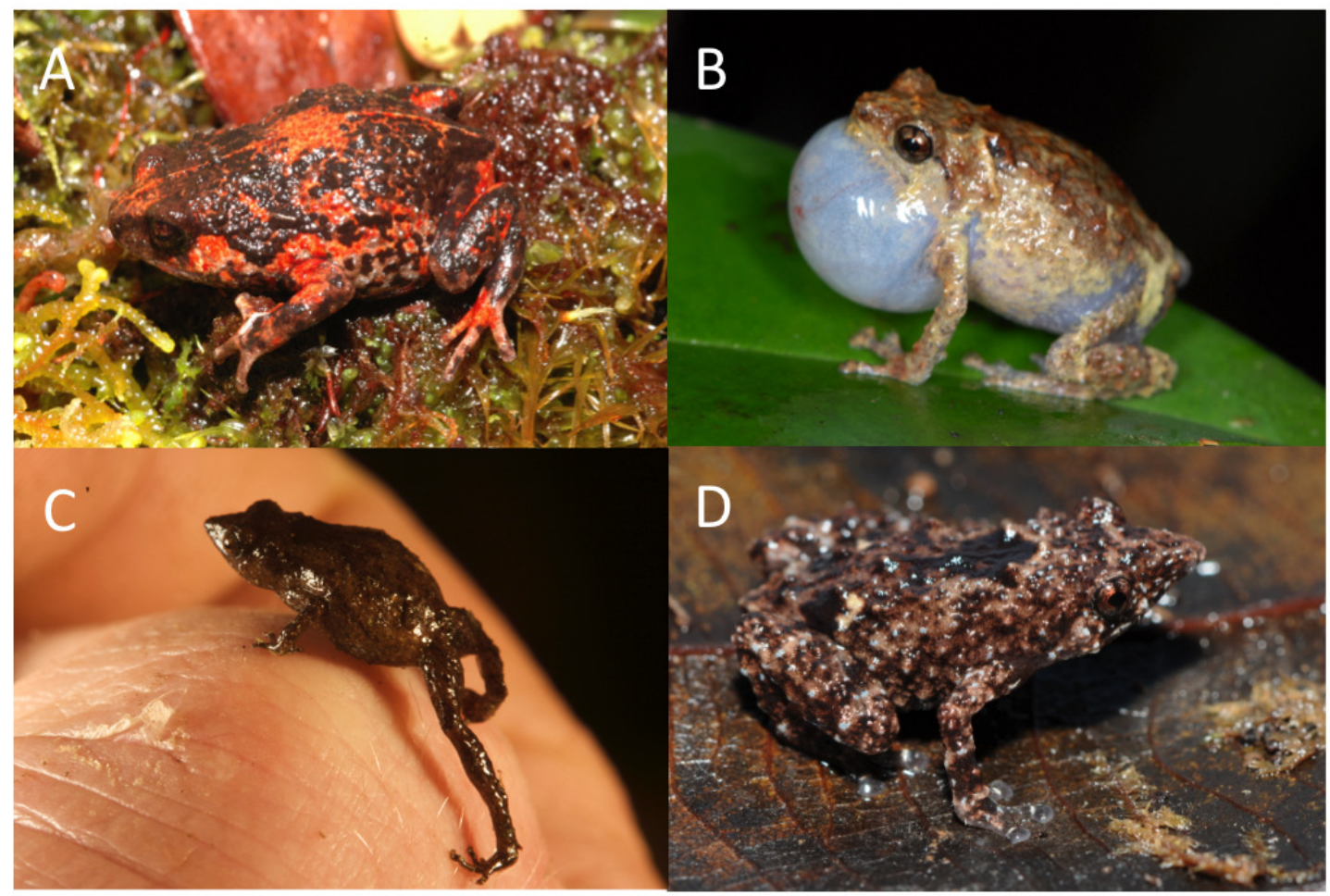

805

806

807

808

809

810 
811

\section{Figure 3. Maximum Likelihood Tree of Choerophryne.}

$813 *$ indicates $<50 \%$ Bayesian posterior probability, interspecific nodes without support values were

814 poorly resolved in both analyses, intraspecific node supports are omitted for clarity. All

815 photographs by S. Richards. 


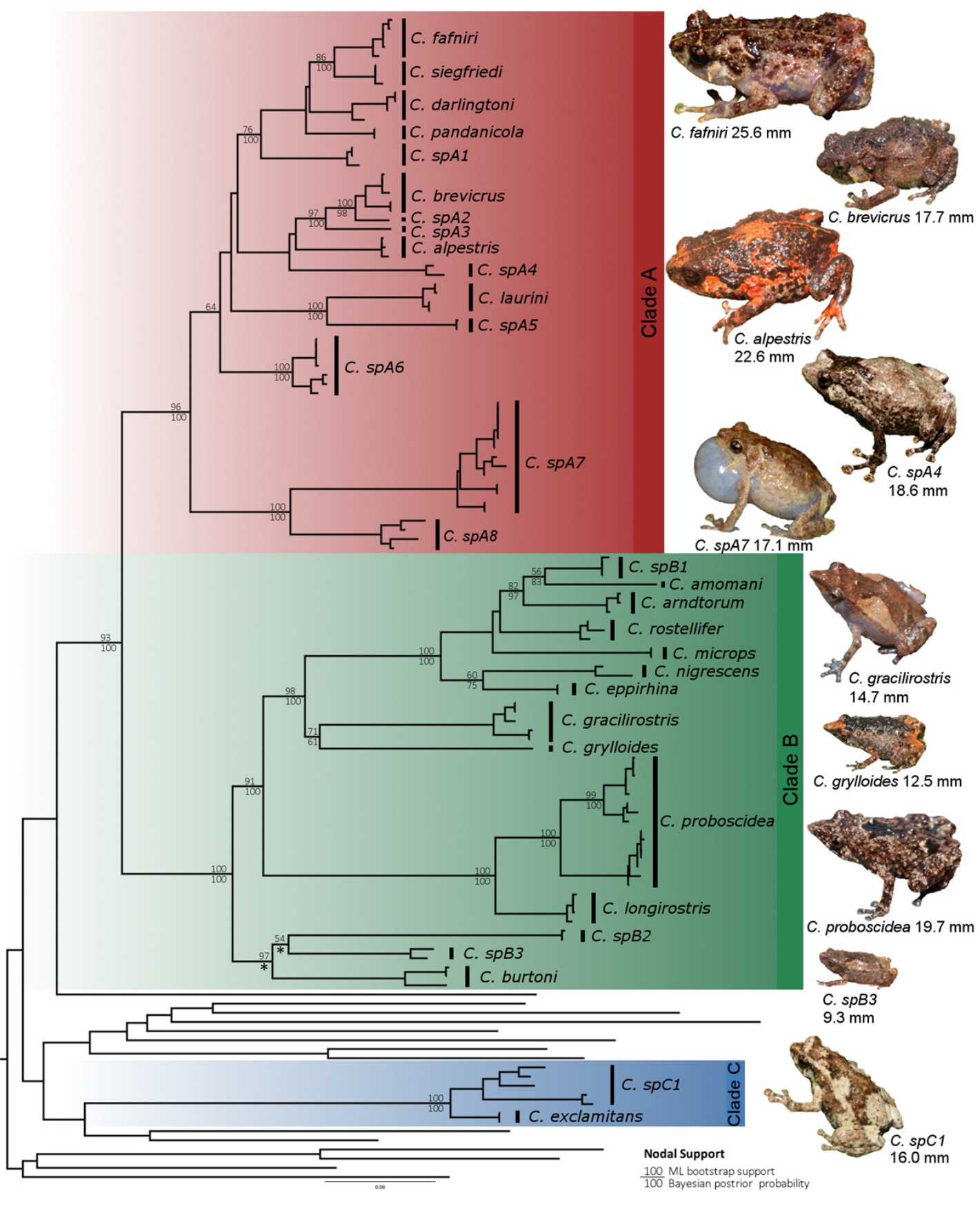

816

817

818 Figure 4. Chronogram and distributional summary for Choerophryne.

819 A) Estimated using 12s and 16s data and rate-based calibration. Node values are Bayesian

820 Posterior Support values from BEAST analysis. Axes along bottom indicate time in millions of 
821 years ago. Branches colour coded based on joint estimates of geographic region and elevation.

822 Four taxa under $15 \mathrm{~mm}$ identified by asterisk. Specific ranges in which inferred eccentric (Clade

823 A) and centric (Clade B) endemics in the North Papuan Mountain ranges are annotated. B) Map

824 of main montane areas of New Guinea, and sampling localities for the three major clades of

825 Choerophyrne.

826 


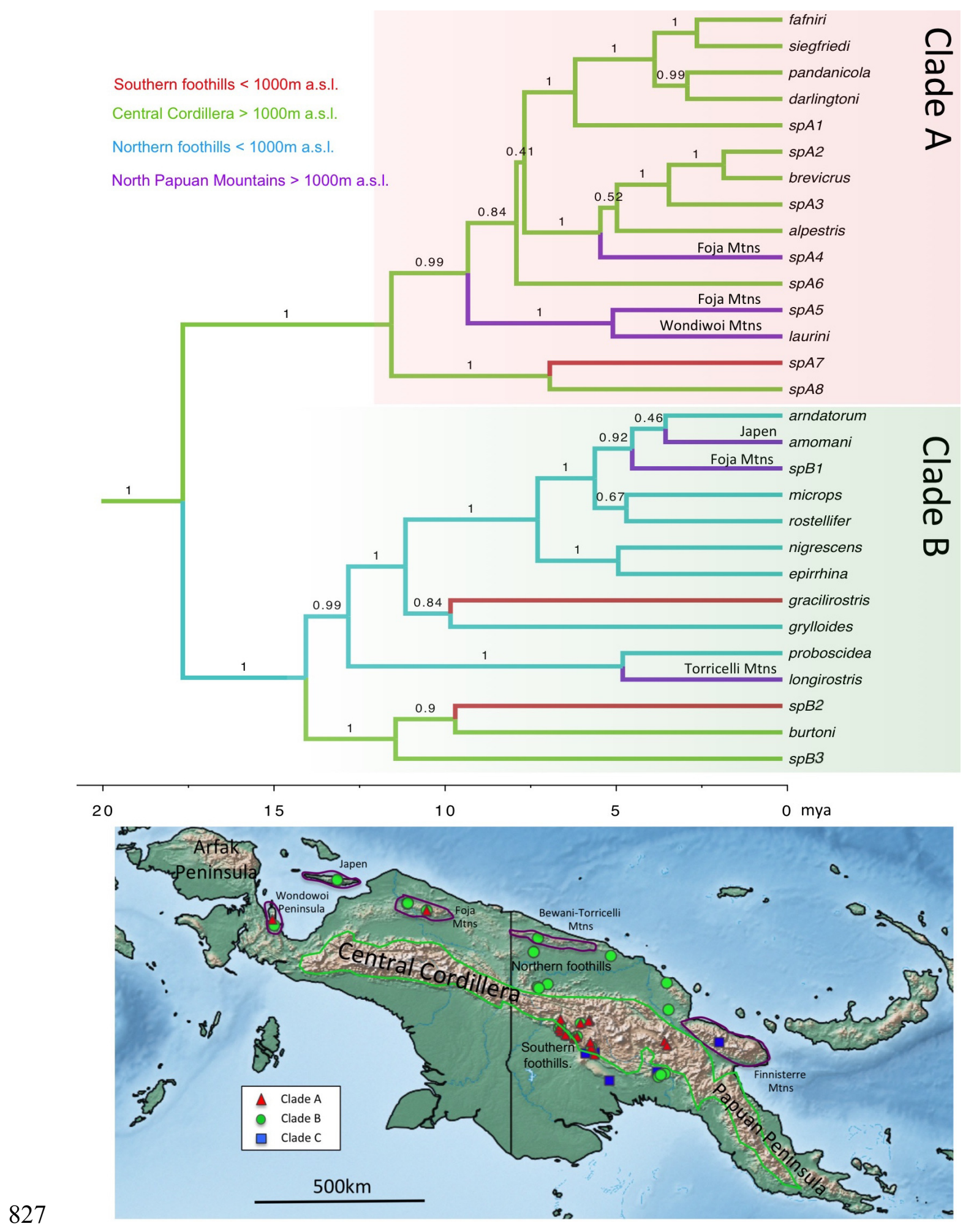




\section{Figure 5. Body size evolution in Choerophryne.}

832 Branch widths are proportional to maximum recorded adult male SVL. Green taxa are larger, red 833 taxa are smaller. Miniaturised taxa $(<15 \mathrm{~mm})$ are indicated with an asterisk. Maximum recorded 834 SUL of males in the genus Choerophryne ranges from $9.3 \mathrm{~mm}$ (spB3) up to $25.6 \mathrm{~mm}$ (C. fafniri). 


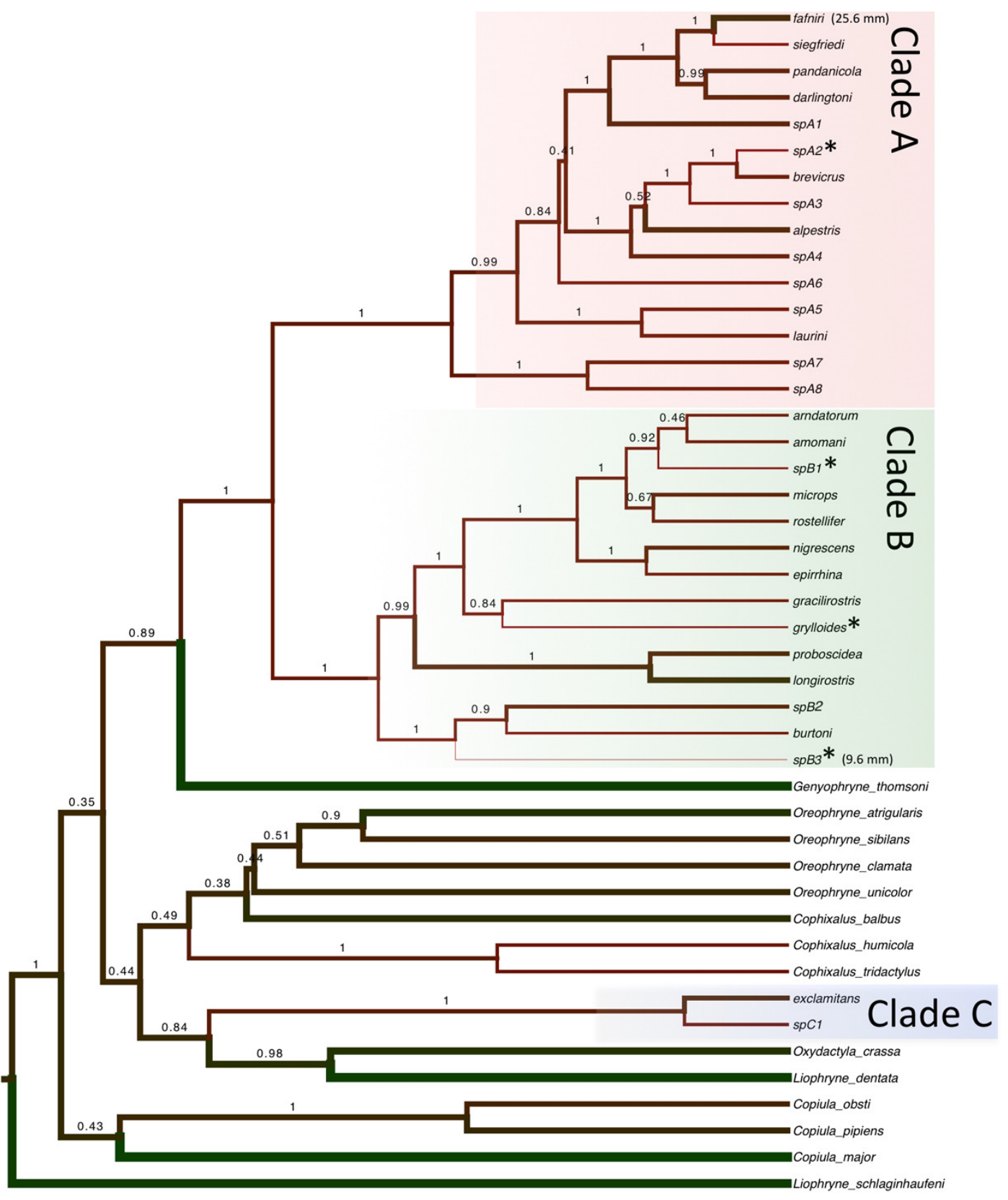

837 